\title{
Air-to-water heat pump assessment: Part 2 - Exergetic and exergoeconomic analyses
}

\author{
Nadezhda Doseva ${ }^{1, *}$, and Daniela Chakyrova ${ }^{1}$ \\ ${ }^{1}$ Varna Technical University, Heat Technology Department, 9000 Varna, Bulgaria
}

\begin{abstract}
This study is part 2 of the investigation on the exergetic and exergoeconomic parameters of an existing system with an air-to-water heat pump unit as a heat source. Part 1 presents the used experimental setup. The main aim of the conducted experimental tests is to develop models of produced heat rate and energetic COP at different ambient conditions. The obtained data is used in Part 2 of the study where the exergetinc and exergoeconomic assessment is carried out. The exergetic and exergoeconomic analysis was performed at dynamically changing ambient parameters. The considered operation modes of the air-to-water heat pump $(A W H P)$ unit and backup heater $(B U H)$ were evaluated based on Seasonal Exergetic Efficiency. For the exergoeconomic analysis, the SPECO method is used. Thus, this paper provides an exhaustive understanding of the exergy and exergoeconomic performance of the considered air-to-water heat pump system.
\end{abstract}

\section{Introduction}

To perform an objective thermo-economical assessment of an energy conversion system, for example, in addition to the quantity of the energy flows, it is necessary to consider and their quality. The main reason for such an approach to the problem lies in the fundamental consequence from the Second Law of Thermodynamics: the different energy forms do not have the same value; they differ in the part that can be converted into another energy form able to do work. Then, the main goal in the design and operation of heating systems should be achieving the maximum exergy content of the product of the analyzed system. On the other hand, in the case of the air to water heat pump (AWHP) system, the higher energy content of the product suggests a higher exergy cost of heating. Therefore, it is necessary to use a method that involves a comprehensive evaluation accounting for the quantities of energy, exergy, and monetary cost. Such an approach is an exergoeconomic method for assessment.

Previous researches [1-6] has established solutions for many problems in the field of the energy performance of AWHP and they provide good practices for the optimal design of air-to-water heat pump systems. However, these investigations provide valuable insights about the rational use of the whole energy flows in the AWHP systems, but, at the same

\footnotetext{
* Corresponding author: nadezhda.doseva@abv.bg
} 
time, they cannot give an accurate description of how this energy is being used and what are the monetary cost of the irreversibility of the conducted real processes.

The application of the exergetic and exergoeconomic methods to the heat pump systems is not a novelty in the reference literature. For example, many studies consider geothermal and solar-assisted heat pumps [7-10]. Suleman et al. [9] conduct comprehensive energy and exergy analyses of the integrated solar and heat pump system. The obtained results show that the coefficient of performance on an energy basis $(C O P)$ of the heat pump cycle is 3.54 whereas the exergy efficiency is $42.5 \%$. Dong, X. et al. [10] prove the statement that the exergy efficiency of the considered in their study solar integrated air source heat pump is $7.9 \%$ higher than the exergy efficiency of the same type of conventional air source heat pump.

The application of the exergoeconomic method is a rarity in the case of the AWHP systems. Bingjie et al. [11] adopt the conventional exergy analysis to the air source heat pump water heater and demonstrate that from an exergetic point of view, the most major component of the system is the compressor because its exergy loss coefficient is the largest in the system (26.12\%). The object of the exergetic analysis in [12] is an air source transcritical carbon dioxide heat pump. The authors of this paper consider the exergy efficiency as a function of the refrigerant charge, and they conduct classical economic and environmental analyses. Although the main aim of these studies is different, they are similar in one thing: the calculated values of the exergy efficiency of the considered AWHP systems are moment's values because they were determined at specified conditions of the reference environment. In this regard, Ozturk et al. [13] perceive a quite different approach: the authors consider the exergy destruction of the AWHP unit components at dynamic change ambient conditions in the heating period. The results in [13] show the variation of exergy destruction through the entire heating period and thus, it can determine the operating conditions of every component for minimizing the irreversibilities.

The idea for the seasonal exergy efficiency of the heat pump unit was introduced by Lizarraga et al. [14]. However, there is a need to apply this concept to the concrete AWHP system and thereby investigate the usefulness of this method for exergy assessment. Therefore, the objective of the current paper is to provide the methodology combining the concept for the seasonal exergetic efficiency of the AWHP systems with the exergoeconomic method. For this purpose, first, in Part 1 of the investigation, the basic energy characteristics of the observed AWHP system (such as energetic COP and produced heat transfer rate) were examined experimentally under dynamically changing parameters of the environment. Then, the method for calculation of the seasonal exergetic efficiency of the AWHP systems is proposed. This method involves the basic insights from previous publications [14-16]. Finally, the method for the determination of the seasonal exergy efficiency of the AWHP systems is supplemented with an approach for exergoeconomic evaluation.

\section{Method}

\subsection{Seasonal Exergetic Efficiency of the AWHP}

In the process of conduction of the exergy analysis, the AWHP unit is considered as a Grassman's thermodynamic box shown in Figure 1 with $n$ input and $m$ output exergy rate flows. In this analysis, the environment is no meaning to the corresponding concept of thermodynamics, because its parameters (temperature, pressure, humidity) are variable. 


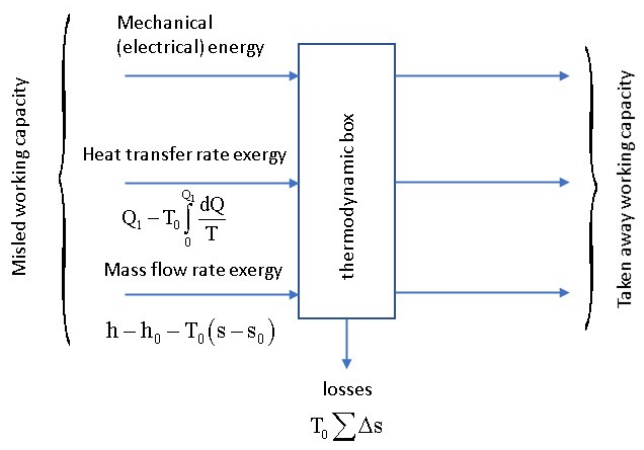

Fig. 1. Grassman's thermodynamic box.

To drive a heat pump can be used mechanical or electrical energy. The rate of these energy flows can be considered equal to the exergy rate of the mechanical or electrical energy flows [15], i.e., $\dot{W}_{e l}=\dot{E} x_{W, e l}$ and $\dot{W}_{\text {mech }}=\dot{E} x_{W, \text { mech }}$. On the other hand, waste heat or heat is taken from the environment can be used as a heat source. In AWHP, from the heat source is taken only anergy, because, in this case, the exergy transfer accompanying heat transfer is zero, $\dot{E} x_{Q_{0}}=0$. Therefore, the moment's value of the exergy efficiency $\left(\eta_{e x, i}\right)$ of an AWHP is:

$$
\eta_{e x, i}=1-\frac{\dot{E} x_{D, A W H P}}{\sum \dot{E} x_{\text {in }}}=\frac{\sum \dot{E} x_{\text {out }}}{\sum \dot{E} x_{\text {in }}}=\frac{\dot{E} x_{Q N}}{\dot{E} x_{W, e l}+\dot{E} x_{Q_{0}}}=\frac{\dot{E} x_{Q N}}{\dot{W}_{e l}}=\frac{\dot{E} x_{Q N}}{\dot{Q}_{N}-\dot{Q}_{0}},
$$

where: $\dot{E} x_{D}$ - exergy destruction rate within the AWHP unit, W;

$\dot{E} x_{Q N}=\left(1-\frac{T_{0}}{T_{N}}\right) \cdot \dot{Q}_{N}$ is the exergy of the produced heat power rate, W;

$T_{0}$ - temperature of the heat source, $\mathrm{K}$;

$T_{N}$ - temperature of the heat sink, K;

$\dot{Q}_{N}$ - produced heat rate, $\mathrm{W}$;

$\dot{Q}_{0}$ - ambient heat rate used as the heat source of the heat pump, W.

After a mathematical transformation of equation (1) is obtained:

$$
\begin{aligned}
& \eta_{e x, i}=\frac{\dot{E} x_{Q N}}{\dot{Q}_{N}-\dot{Q}_{0}} \mid: \frac{\dot{Q}_{N}}{\dot{Q}_{N}} \\
& \eta_{e x, i}=\frac{\left(T_{N}-T_{0}\right) / T_{N}}{1-\omega}=\frac{\left(T_{N}-T_{0}\right) / T_{N}}{1 / C O P_{\text {eff }}}
\end{aligned}
$$

where: $\omega=\dot{Q}_{0} / \dot{Q}_{N}=\left(\dot{Q}_{N}-\dot{W}_{e l}\right) / \dot{Q}_{N}=1-\left(1 / C O P_{e f f}\right)$; $C O P_{\text {eff }}$ - effective coefficient of performance on the energy basis.

The value of the $C O P_{\text {eff }}$ depends on the operating mode of the heat pump mode (i.e., full load, partial load, or on-off cycles) and the method of its calculation is detailed 
discussed in a previous study [17]. The used approach for the determination of energetic $C O P$ and $Q_{N}$ of currently considered AWHP is presented in Part 1 of the study. Here, the developed mathematical models are used to perform the calculations by equations (3) and (4).

In eq. (2), the term $\left(T_{N}-T_{0}\right) / T_{N}$ is nothing but the coefficient of performance of the ideal heat pump cycle. Therefore:

$$
\eta_{e x, i}=\frac{C O P_{e f f}}{C O P_{C A R N O T}}=1-\frac{E x_{D, A W H P, i}}{\dot{W}_{e l, i}}
$$

where : $E x_{D, A W H P, i}$ - exergy destruction within the system at $i$-th ambient temperature, W.

Equation (3) gives the moment's value of the exergetic efficiency of the considered AWHP system because it is calculated at specified conditions of the environment. In the current investigation, this moment's values are used to determine the seasonal exergetic efficiency of the AWHP system.

Based on the views of other authors [14], the seasonal exergetic efficiency of the AWHP unit can be written:

$$
S \eta_{E X}=\frac{\sum E x_{Q_{N}}(i)}{\sum W_{e l}(i)}
$$

where: $\sum W_{e l}(i)=\sum_{i=1}\left(\dot{W}_{e l, i} \cdot \tau_{i}\right)$ - electrical energy input to the AWHP unit in the heating period, kWh;

$\sum E x_{Q_{N}}(i)=\sum_{i=1}\left(\eta_{e x, i} \cdot \dot{W}_{e l, i} \cdot \tau_{i}\right)$ - the exergy of the produced heat rate in the heating period or heating exergy demand of the building, $\mathrm{kWh}$;

$\tau_{i}$ - the duration of the $i$-th outdoor temperature bin, h.

\subsection{Methodology for exergoeconomic analysis of AWHP systems}

In this study, the exergoeconomic analysis consists of the conventional exergy analysis and economic analysis. The aim is to reveal the process of cost formation and evaluate the exergy cost of the produced useful heat. This calls for the formulation of cost rate balances for the considered AWHP system. For an AWHP unit operating during the heating period with duration $\tau_{H P}$ can be written:

$$
\begin{gathered}
c_{p, H P} \cdot \frac{\sum E x_{Q_{N}}(i)}{\tau_{H P}}=\dot{Z}_{A W H P, H P}+c_{F} \cdot \frac{\sum W_{e l}(i)}{\tau_{H P}} \\
c_{p, H P} \cdot \frac{S \eta_{E X} \cdot \sum W_{e l}(i)}{\tau_{H P}}=\dot{Z}_{A W H P, H P}+c_{F} \cdot \frac{\sum W_{e l}(i)}{\tau_{H P}}
\end{gathered}
$$

where: $Z_{A W H P, H P}$ is levelized costs of the capital investment, operating and maintaining of the AWHP system per unit time (hour) during the heating period, $€ / \mathrm{h}$;

$c_{p, H P}$ and $c_{F}$ - seasonal exergetic cost of the product of the system and of the fuel, respectively, $€ / \mathrm{kWh}$.

The levelized costs of the capital investment, operating and maintaining of the AWHP system per unit time (hour) during the heating period are determined as follow:

$$
\dot{Z}_{A W H P, H P}=\left(P E C_{H P} \cdot C R F \cdot \varphi\right) / \tau_{H P}
$$

where: $P E C_{H P}$ - the initial investment costs for the heat pump unit. It is defined according to the official price list of the manufacture [18], $€$; 
$C R F=\frac{i \cdot(i+1)^{n}}{(i+1)^{n}-1}-$ capital recovery factor $[19] ;$

$i=6 \%$ - the real discount rate;

$n$ - the economic life of the heat pump system. It is assumed to be $n=15$ years;

$\varphi=1.06$ - maintenance factor [19];

$\tau_{H P}$ - duration of the heating period, $\mathrm{h}$.

According to the previous investigation of the authors [20], it is proved that the duration of the heating period in Varna, Bulgaria is $\tau_{H P}=4582 \mathrm{~h}$.

\subsection{Climatic data}

Because the experiment in Part 1 of the investigation is carried out for a range of ambient temperature $\left(t_{e}=2.03^{\circ} \mathrm{C} \div 11.78{ }^{\circ} \mathrm{C}\right)$, to obtain a complete picture of the exergetic and exergoeconomic behavior of the AWHP system, it is necessary to be considered a wider external air temperature range.

In the current paper, the heat exergy requirement of the building, $E x_{Q N}$, dependent on the temperature operating conditions is determined after by assessment of the ambient temperature. This evaluation consists of obtaining the cumulative frequency of the external air temperature within a typical heating period. For this purpose, the data for the frequency of the external air temperature within the heating period is used. The input data used (i.e., the frequency of the external air temperature) for Varna, Bulgaria is published in a previous study [20].

The cumulative frequency for Varna, Bulgaria is obtained by summed-up bin-by-bin the frequency of the external air temperature within the heating period:

$$
N_{k}=\sum_{i=1}^{k} n_{i}
$$

where :

$N$ - cumulated number of hours;

$k$ - number of the considered bin;

$n_{i}$ - number of hours for the considered bin.

The cumulative frequency of the external air temperature is shown in Figure 2.

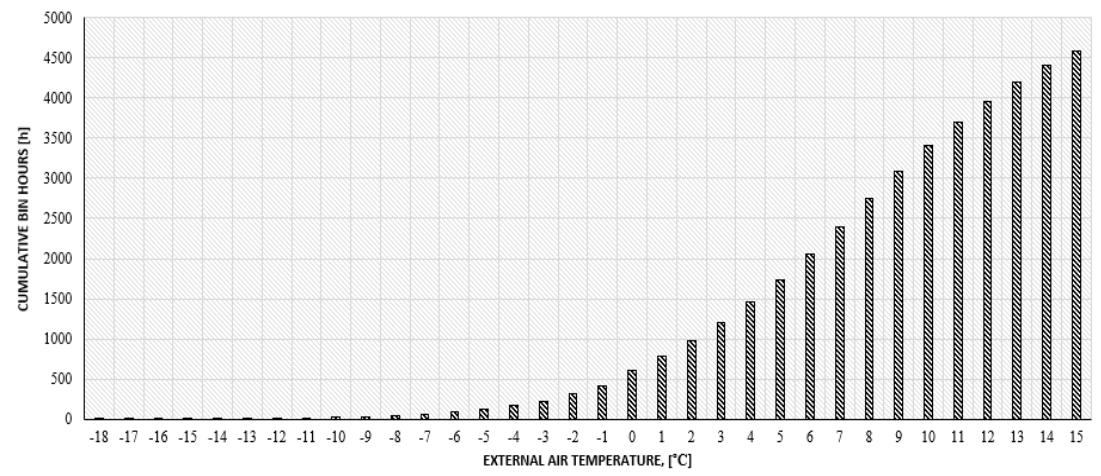

Fig. 2. Cumulative frequency of the external air temperature in the heating period - Varna, Bulgaria 
In the context of the obtained in Part 1of the study results regarding PLR, the operation modes of the AWHP can be defined. In case it is assumed that the design temperature is the lowest of the observed values, i.e. $-18^{\circ} \mathrm{C}$, from Figure 3 follows that $2676 \mathrm{~h}$ the AWHP unit will be operated at part load. At the same time, there is $89.2 \mathrm{~h}$ in which the heat capacity of the AWHP will be insufficient to meet the energy needs of the building.

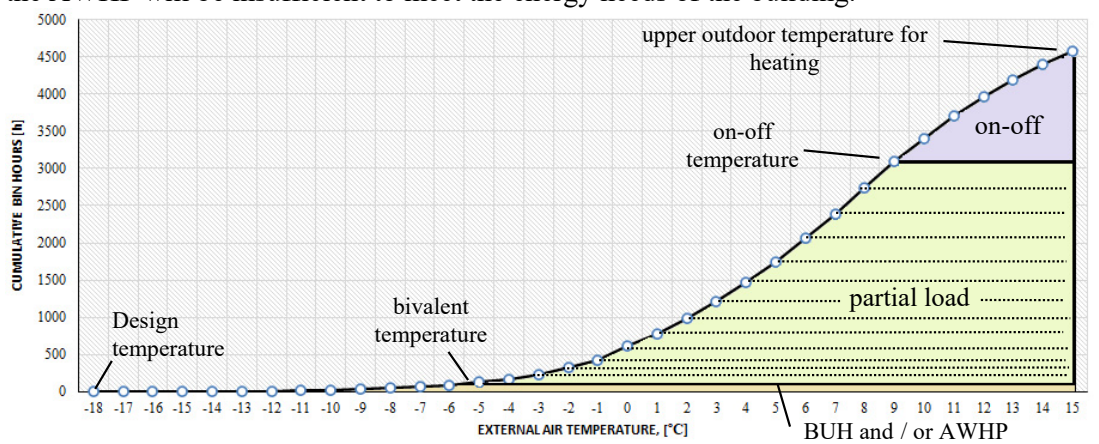

Fig. 3. Bin hours for alternate or partly parallel operation mode of the back-up heater (BUH) - Varna, Bulgaria

Moreover, according to the methodology for determination of outlet temperature of the heat transfer medium (presented in Part 1 of current investigation), it is predicted that at ambient temperatures $t_{e}<-14^{\circ} \mathrm{C}$, the outlet temperature, $t_{w, e}$, will be in the range $49^{\circ} \mathrm{C} \div 51^{\circ} \mathrm{C}$. At these operating conditions (i.e., the values of $t_{e}$ and $t_{w, e}$ ), however, the operating limit temperature $(T O L)$ of the AWHP unit is $-15^{\circ} \mathrm{C}$. This allows the conduct of exergetic and exergoeconomic analyses for two different cases: partly parallel and alternate operation mode of the backup heater.

In the current paper is assumed that at alternate operation mode of the back-up heater $(\mathrm{BUH})$, the AWHP unit is switched-off at bivalent temperature $t_{b i v}=-5.73{ }^{\circ} \mathrm{C}$, and only the BUH covers the full energy requirement of the building. At partly parallel operation mode of the BUH, the AWHP is not switched-off at $t_{b i v}=-5.73^{\circ} \mathrm{C}$. The AWHP unit and the BUH operate in parallel mode up to $T O L$, and at an ambient temperature lower than $-15^{\circ} \mathrm{C}$ only the BUH operates.

It is important to note, that the AWHP on-off operation mode is not considered in the current investigation. The reason is the limited number of measurements within an interval $t_{e}>9{ }^{\circ} \mathrm{C}$. Therefore, the obtained model of energetic COP does not cover this operation mode. In addition, the previous part of the investigation established that the balance temperature is $t_{\text {balance }}=21.08{ }^{\circ} \mathrm{C}$. This is the ambient temperature at which $P L R=0$. However, in part 2 of the study is assumed that the upper outdoor temperature for heating is $15^{\circ} \mathrm{C}$. Thus, the performed analysis is closer to the real conditions under which the heating of buildings is realized.

\section{Results and discussion}

According to the concept of seasonal exergetic efficiency expressed by equation (4), the considered operation modes of the BUH and the AWHP were evaluated. The results are presented in Figure 4 using Grassman's diagrams. From this data, it can see that the alternate operation mode of the BUH results in the lower value of the seasonal exergetic efficiency: $S \eta_{E X}=30.6 \%$ in the case of the partly parallel operation mode of the BUH and $S \eta_{E X}=29 \%$ for alternative operation mode, respectively. 

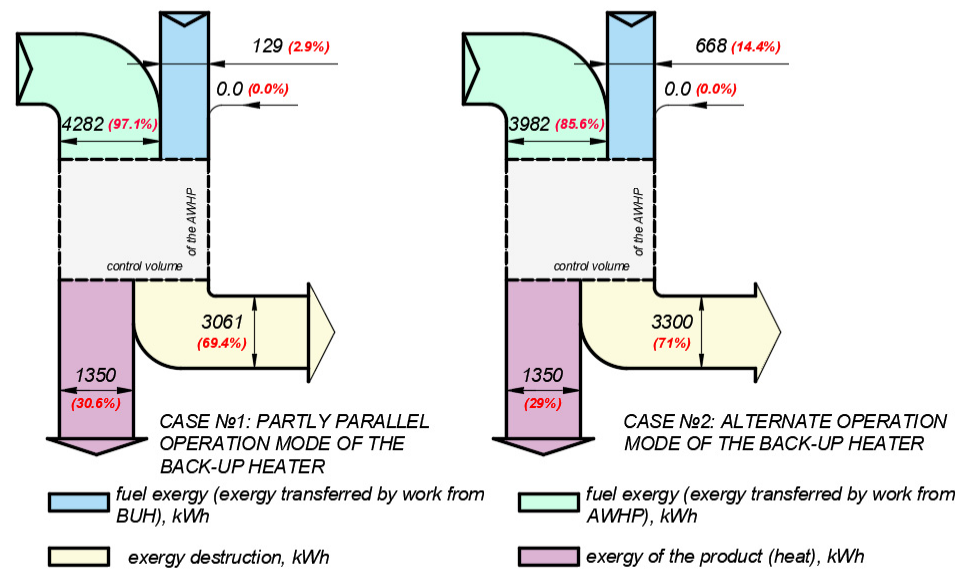

Fig. 4. Grassman's diagram of exergy flows considering the heating season.

This leads to the conclusion that if the AWHP unit operated for a longer period in the heating season, this is more efficient from an exergetic point of view.

Figure 5 provides information about the cost rate associated with the exergy of the fuel (electrical energy) and the product (heat). As can be expected, due to the higher value of $S \eta_{E X}$ in Case №1 (the partly operation mode of the BUH), the cost rate associated with the product, $\dot{C}_{p}$, is lower than the one in Case №2 (the alternate operation mode of the BUH). The unit exergy cost of the product, $c_{p}$, during the considered heating period is $1.11 € / \mathrm{kWh}$ in Case №1 and $1.14 € / \mathrm{kWh}$ in Case №2, respectively.
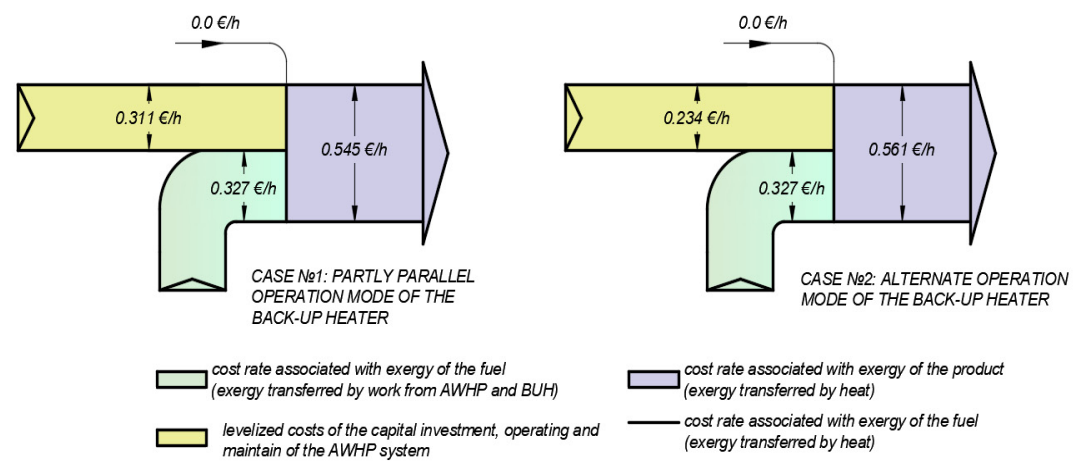

Fig. 5. Cost flow diagram of the AWHP system operating during the heating season.

Overall, the presented results suggest the statement that the switch-off temperature of the AWHP unit plays a vital role in the seasonal efficiency of the system. The seasonal exergetic coefficient of performance rise around $5.16 \%$ when the switched-off temperature 
is decreased from $t_{e}=-5.73{ }^{\circ} \mathrm{C}$ to $t_{e}=-15^{\circ} \mathrm{C}$, whereas the cost rate associated with the product of the AWHP system realize a $3.1 \%$ drop.

A closer inspection of the moment's values of the $\eta_{E X}$ at partial operation mode of the AWHP as a function of the external air temperature (Figure 6) indicates an unexpected outcome: there is a maximum value of $\eta_{E X}$. The highest moment's values of the $\eta_{E X}$ at partial operation mode is equal to $34.1 \%$ and it is observed at external air temperature $t_{e}=$ $-2.573^{\circ} \mathrm{C}$ and temperature of the produced heat transfer medium $t_{w, e}=42.54^{\circ} \mathrm{C}$.

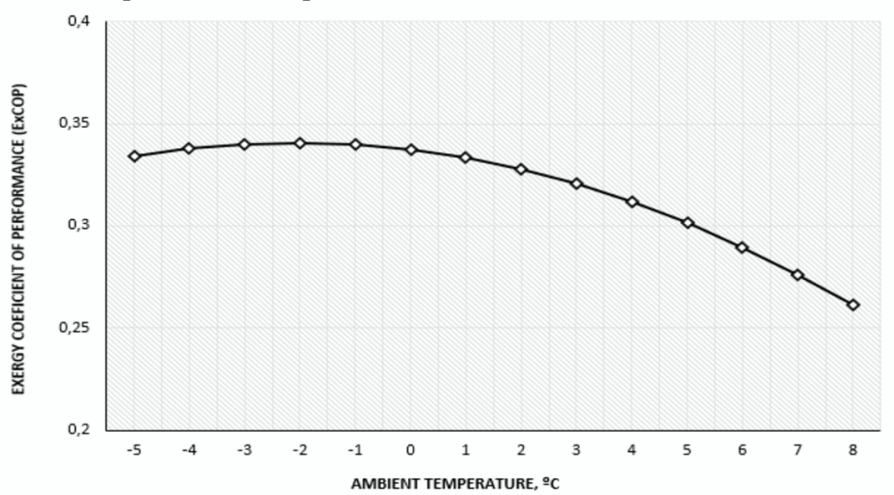

Fig. 6. Moment's values of the exergetic efficiency at partial operation mode of the AWHP as a function of ambient temperature.

The maximum of $\eta_{E X}$ can be explained considering the derivative of exergy efficiency. From the graph in Figure 7, it can be seen that the derivative of the exergy efficiency changes its sign, which indicates the presence of an extremum of the function. The value for the outside air temperature at which the extremum is obtained is calculated from the equation of the derivative. Physically, this phenomenon is explained by the fact that the rates of decreasing of the exergy used in the heated space and the external exergy inputted into the process are different. The input exergy has a significantly higher rate of decreasing than the produced exergy, which at some point changes the tendency of change of the exergy efficiency. On the contrary, the energetic $C O P$ gradually rises with the external air temperature increase.

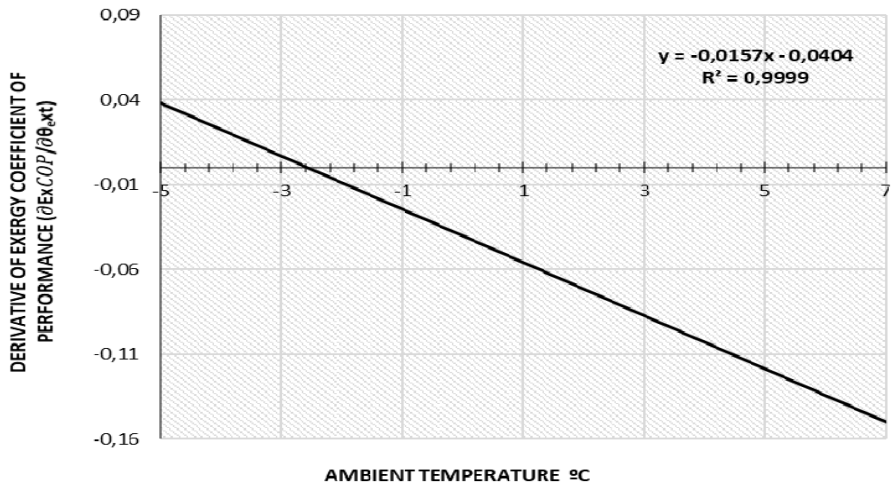

Fig. 7. Derivative of exergy performance coefficient $\left(\partial \eta_{E X} / \partial t_{e x t}\right)$ as a function of the ambient temperature. 


\section{Conclusions}

The main objectives of Part 1 and Part 2 of the current investigation were to provide a methodology for seasonal exergetic and exergoeconomic assessment of air-to-water heat pump systems using the experimental data. The obtained results demonstrate the usefulness of the exergy-based assessments.

Furthermore, this study is indicative that from a thermodynamic point of view, there is no heat transferred from a renewable energy source. The second law of thermodynamic said that all heat transferred processes are spontaneous or non-spontaneous. Therefore, the use of all so-called renewable energies becomes possible because of the realization of heat transfer in a spontaneous process between the environment and the considered thermodynamic system. A clear example of this statement is the use of solar energy in thermal engineering systems. However, the current paper can be considered as a demonstration of the exception to the rule described above. That exception is in the case of heat pumps: the utilizing of aerothermal energy by a heat pump is possible after occurring a non-spontaneous heat transfer process. At this non-spontaneous process between the environment and control volume (the AWHP unit), the exergy of the fuels (electrical energy) is consumed to produce the useful heat (exergy of the product) and to cover exergy destruction within the system. The produced heat power, on the other hand, consists of the exergy and anergy. The exergy content of the product is used to maintain the indoor air temperature, whereas the anergy (the irreversible part of the heat) taken from the ambiance is returned to the environment in form of heat loss through the building envelope. A consideration of the heat pump systems in similar aspect can bring additional insights into the thermodynamic description of their operating modes as well as into the aims in the process of their optimization.

\section{References}

1. Dongellini, M., Naldi, C., Morini, M. IBPC 2015, 78 (2015).

2. Naldi, C., Dongellini, M., Morini, M. ATI 2014, 81 (2015).

3. Naldi, C., Dongellini, M., Morini, M. IBPC 2015, Energy Procedia 78 (2015).

4. Vocale, P., Morini, G., Spiga, M. ATI2013 45 (2014).

5. Dongellini, M., Naldi, C., Morini, G. J. Appl. Therm. Eng. 114 (2017).

6. Dongellini, M., Impala, V., Morini, G., 16th International Conference on Sustainable Energy Technologies - SET 2017 (2017).

7. A. Hepbasli, O. Akdemir, Energ Convers Manage, 45, 737 (2004).

8. Y. Bi, X. Wang, Y. Liu, H. Zhang, L. Chen, Appl Energ, 86, 2560 (2009).

9. F. Suleman, I. Dincer, M. Agelin-Chaab, Appl Therm Eng, 73, 559 (2014).

10. X. Dong, O. Tian, Z. Li, Energ Buildings, 142, 128 (2017).

11. M. Bingjie, L. Qinghai, C. Guojie, 4th International Conference on Sensors, Measurement and Intelligent Materials (ICSMIM 2015), 197 (2016).

12. Y. Wang, Z. Ye, Y. Song, X. Yin, F. Cao, Energ Convers Manage, 223, (2020).

13. M. Ozturk, B. Doğan, L. Erbay, Sustainable Energy Technologies and Assessments, 42, (2020).

14. J. Lizarraga, A. Picallo-Perez, Exergy Analysis and Thermoeconomics of Buildings. Design and Analysis for Sustainable Energy Systems (Book, Elsevier, 2020). 
15. W. Eder, F. Moser, Die Wärmepumpe in der Verfahrenstechnik (Bulgarian edition, 1984).

16. D. P. Gohshteyn, Modern methods of thermodynamic analysis of power plants, (Energia, Moskow, 1969).

17. N. Doseva, D. Chakyrova, E3S Web of Conferences, 207, (2020), Article number 01014 25th Scientific Conference on Power Engineering and Power Machines, PEPM 2020; Sozopol; Bulgaria, 2020.

18. ClimaCom. Ecodan Price List 2020/2021 (2020). [Online], available at https://climacom.com/en/price-lists

19. Bejan A, Tsatsaronis G, Moran M., Thermal design and optimization (Wiley, New York, 1996).

20. D. Chakyrova, N. Doseva, N. Kalcheva, CIEES International Conference, (2020) https://iopscience.iop.org/article/10.1088/1757-899X/1032/1/012024 ISSN 1757 899X 